\title{
Treatment Option or Pharmacological Wager?
}

\section{Ann Boyd*}

Hood College, Frederick, USA

A 21 year old male (JB) had severe pain in his back and side and a confined rash along the left side of his spine. Doctor at a walk in clinic diagnosed Shingles. The patient had chickenpox at age 6 months, and Shingles is a recurrent herpes zoster virus infection (the same virus which causes chickenpox). JB was given three prescriptions. One prescription for pain, and two formulations of acyclovir, a standard anti-herpes virus drug, one in tablet to be taken by mouth, the other in an ointment to be applied to the rash. The oral form was available in generic version for about $\$ 40.00$ and the pain medication was similarly priced. The ointment however was $\$ 800.00$ without prescription insurance (\$200.00 with insurance). Having insurance coverage on his mother's policy and no chronic illness, JB lacked prescription coverage, and called me for advice (I am his grandmother). The pharmacist informed us that the oral antiviral was usually sufficient without the ointment. After consulting with the pharmacist he elected to go with the oral formulation without the cream.

As we were leaving the store, JB turned to me and asked why the same drug in pill was cheaper than in the cream. The answer is simple. The oral drug has outgrown its patent restraint whereas the cream is still under patent. Fortunately this case ended well. He cleared the infection within 10 days. This is a simple case where everything worked out well but it could have been much more serious.

Suppose that the same young male had leukemia rather than Shingles. While pharmacological companies clearly are for profit firms with boards of directors and investors to satisfy they are also entrusted to develop useful drugs to treat people when they are ill. Patent legislation assures the company will recover their investment but it refrains from setting a ceiling on profit. All over the world there are people with treatable illnesses. How many of them simply cannot afford the patent price of their treatment?

Nations exist to protect its people. And countries with a national healthcare system allocate treatment on a variety of policy standards. The United States is the only developed country that still struggles to justify to its citizen's universal healthcare. Progress on this issue is painfully slow being hostage to political contest of will to power more than compassionate regard for the people who entrusted them with such power.

What reasonable answer should we offer to any person with an illness that we can treat when such treatment is only available if insured or the patient can afford the medication? Regrettably there are strident voices that either blame the sick for their condition or turn a blind eye saying work hard and you can afford treatment. Such answers risk prejudice in the direction of social worth rejecting claims of those in need as a consequence of their free will actions. A corrective in perspective would come from the view that every person is the product of a birth lottery meaning no person selects in advance their genetic family or their unique capabilities. The preferable alternative is to say that every sick person counts as person whose dignity requires access to medical care. To offer everyone treatment means all workers contribute so that all have access. If everyone is covered and eligible for care it will be necessary to limit healthcare expenses by collectively doing what the insurance companies do currently: negotiate what they will pay for a given drug. If the nation sets prices through such negotiations it would be reasonable to expect some profit limits in the current patent system. Collective accountability and responsibility to fund health care for all would avoid expensive emergency treatments and may in time save health care investments so that universal access is cost effective and sustainable.

The case of Shingles raises a couple additional points. The younger part of the population does not expect to get sick and gamble that they don't need insurance or prescription coverage. Age does not seem a guarantor against this exceptionality perspective. People overeat, skip physical conditioning, smoke, drive at excessive speeds, and seem genuinely shocked if they develop hypertension or are injured in a car accident.

Knowing and recognizing our vulnerability to unexpected illness or need of medical care is an essential step in using healthcare as a trust and not a gamble token. In a capitalistic society that prizes individual freedom over the common good it is easy for the big pharma companies to set prices as high as they like because they wager a family member will love the patient enough to find the money for treatment. The people who set these policies are sure they get coverage and will not be in need but they may be self-deceived in their assessment of job security and or their individual health status. Until the patient that is a stranger has the same moral claim to care as their beloved family member or oneself, the struggle for universal care is likely to continue.

The most dedicated advocate for individual freedom should see that universal coverage is good for them in case they needed it but that turns out to be a difficult lesson. I have worked for 40 years and had insurance deducted from my wage like taxes and fortunately never been unemployed and thus uninsured. I do not think I am special in this respect but have been privileged not by merit as much as by chance.

If my grandson had needed the expensive cream I could have afforded it, and I let him decide.

Despite the simplicity of the case it has haunted me because his situation could have been much worse and the medicine needed unaffordable. What does a mother say to a child when he is sick and she cannot afford the medicine? What child deserves to suffer? Sadly, many do.

Ethics offers reasoned discourse on issues that concern the wellbeing of persons. Health is a precondition to human flourishing and as such deserves the status of a human right. It may be open to question what degree or extent of investment is necessary or what degree of health can

*Corresponding author: Ann Boyd, Hood College, Frederick, USA, E-mail: boyd@hood.edu

Received August 09, 2013; Accepted October 21, 2013; Published October 27 2013

Citation: Boyd A (2013) Treatment Option or Pharmacological Wager? J Clin Res Bioeth 4: 161. doi:10.4172/2155-9627.1000161

Copyright: (c) 2013 Boyd A. This is an open-access article distributed under the terms of the Creative Commons Attribution License, which permits unrestricted use, distribution, and reproduction in any medium, provided the original author and source are credited. 
be attained for everyone. Decisions about strategies and quantitative methods of allocating health care resources ought to emerge from engaged civil conversation within the whole community. The system is complex as are the patients who are persons. If allocation is according to need it is clear that some will receive more than others simply because the need is greater. We should not resent that some folks will need more expensive care, but rejoice that we are well and do not need it. If each person is given a voucher for $\mathrm{x}$ value of coverage, and their medical needs exceed that allotment, it seems that the suffering is merely delayed rather than addressed as a human need. More reasonable is the notion that disease categories have a standard of care that is given to everyone with that disease, where ceilings can be set in treatment based on life years gained, risk-benefit assessment. Limits would be set by necessity. Futility rules would be reasonable when a treatment fails to alter the progression of the disease or its outcome.

It is unsustainable to have a maxim such as, "do everything possible for everyone, everywhere". Such a maxim would bankrupt any nation.
Therefore procedures and treatments would be offered according to need and an expected outcome in some quantifiable way. A quantitative approach with clear criteria for efficacy should be used to decide what expense to invest to promote the flourishing of the patient with a wide lens view of what we can sustain if everyone with a similar condition is treated equally.

I propose that the grounding for such an allocation within a universal coverage policy would reduce cost of care and improve overall healthcare statistics in my country. Every patient is a person whose dignity is due respect. I find it easier to forgive the invincibility and self-deception of a person 21 years of age than a 51 year old. Decades of life offers us enough experience that we should learn that we too can be sick, dependent on the care of strangers, at least enough to enact safety nets for all. Dignity is a quality we ascribe to human beings and it is a grave injustice to ignore it. 